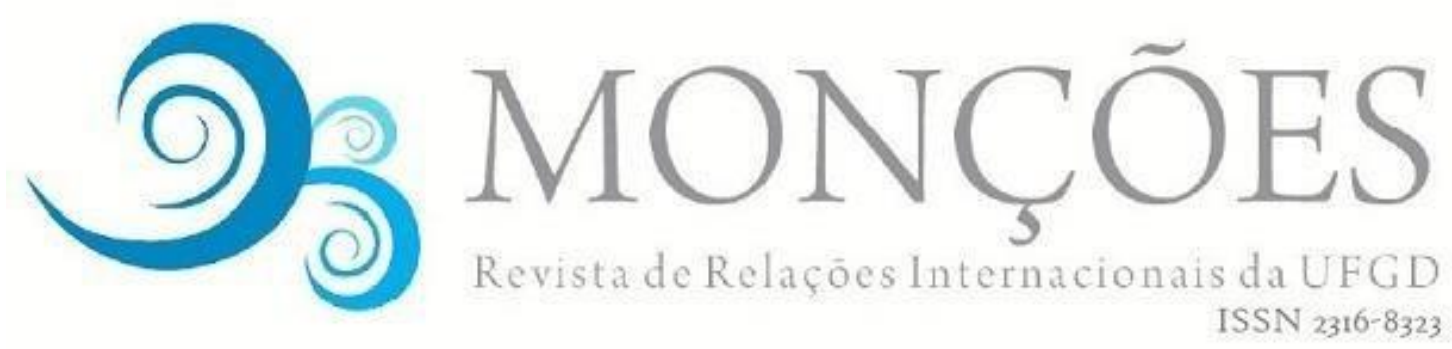

\title{
RESENHA: ESPAÇOS TRANSFRONTEIRIÇOS E INTEGRAÇÃO NA AMÉRICA LATINA: UMA ANÁLISE DE "REPENSAR LAS FRONTEIRAS, LA INTEGRACIÓN REGIONAL Y EL TERRITÓRIO"
}

ACOSTA, Willy (org).. Repensar las fronteras, la integración regional y el território', Costa Rica/Buenos Aires: IDESPO/CLACSO, 352 pgs., 2017.

MARCOS ANTONIO DA SILVA

Professor do curso de Ciências Sociais e do programa de pós-graduação em Sociologia da Universidade Federal da Grande Dourados (UFGD) e Rio Grande do Norte (UFRN). Membro do LIAL/UFGD (Laboratório Interdisciplinar de Estudos sobre América Latina).

\begin{abstract}
"Yo no quiero un cuchillo en manos de la patria. Ni um cuchillo ni un rifle para nadie: la tierra es para todos, como el aire".

"Creo que los países serán un solo sitio de amor para los hombres, a pesar de los pactos, a pesar de los límites, los cónsules, a pesar de los libres que se dan por esclavos". (Jorge Debravo, pg. 11 e 16).
\end{abstract}

A temática das fronteiras se constituiu num dos temais fundamentais das ciências sociais e das relações internacionais e adquire uma relevância crescente no mundo contemporâneo, por envolver uma série de elementos e desafios que compõem a nova ordem mundial como a persistência dos conflitos bélicos, a migração internacional e os refugiados, os efeitos do desenvolvimento desigual e das tensões Norte-Sul, as consequências do aquecimento global, a ocupação forçada de territórios e o aprofundamento dos processos de Integração Regional, dentre outros. Tal processo (e seus desafios) afeta todas as regiões do planeta e, especialmente, a América Latina, pois sua dinâmica e seus efeitos incidem sobre as relações regionais e a persistente dívida econômica e social que afeta os estados latino-americanos. Sendo assim, podese constatar a necessidade de produção e divulgação de pesquisas e reflexões sobre a intricada relação entre fronteiras, territórios e integração regional, que se constitui no objetivo fundamental desta obra e a torna extremamente relevante. 
Para tanto, a obra parte da constatação de que tal temática se insere na dinâmica de construção dos Estados Nacionais e continua presente no mundo globalizado, estando sua análise relacionada a duas abordagens distintas, como aponta Zidaine Zeraoui, na apresentação: "El tema de la frontera, y en particular de los estudios fronterizos, han sido una preocupación constante en los medios académicos internacionales y latinoamericanos. Las tesis van desde el irredentismo nacionalista hasta la idea de un gobierno universal, de un mundo sin fronteras, un "estado-universal-internacional", pero eurocéntrico e imponente, como lo denominó Emmanuel Kant" (pg. 17).

A partir disto, se pode observar que a fronteira é uma construção humana e social, portanto dinâmica e em permanente (re) construção, e se relaciona aos processos contemporâneos, vivenciados de forma específica na América Latina, associados à crise do Estado-nação, às migrações internacionais, ao regionalismo e a integração regional, ao protagonismo indígena e de novas perspectivas que fizeram emergir a noção de 'espaço transfronteiriço', como algo que não pertence a um ou outro estado, a uma ou outra cultura, constituindo-se num espaço de troca (para além do comercial) e impulsionador dos processos de integração regional.

A obra se inscreve nos marcos de atuação dos grupos que compõem o Conselho Latino-Americano de Ciências Sociais (CLACSO) e, especificamente, como parte do projeto de pesquisa "El fenómeno de la integración regional en Relaciones Internacionales: una contribución teórica a la disciplina a partir de la crítica a la colonialidad del poder y el cosmopolitismo", da escola de Relações Internacionais da Universidade de Costa Rica.

Sendo assim, um dos elementos fundamentais de tal obra refere-se a sua inserção na perspectiva decolonial, procurando tratar de 'velhos temas' com uma 'nova mirada' ou de temas locais e emergentes para superar o eurocentrismo de tal temática e a colonialidade do saber que isto implica. Tal abordagem é evidenciada no enfoque geral, na escolha de determinadas temáticas e na composição destas e, finalmente, na análise e no tratamento de questões relacionadas a Ciências Sociais, Estado, Território e Espaço.

Neste sentido, emerge uma obra que procura pensar a região com um olhar próprio e contribuir para a construção de conceitos adaptados a tal 
realidade, como o de lugar, indicado na introdução: "En este contexto de formación de espacios transnacionales, el lugar no es más que un espacio de producción de la vida que se define por su objetividad geográfica; es también un espacio simbólico que revela la complejidad de las dinámicas intersubjetivas y transnacionales... Por el término lugar se entienden, en la crítica poscolonial y antiutilitarista, las formas de experiencias vividas y enraizadas que permiten la organización de conocimientos específicos y plurales, articulados en la vivencia cultural y práctica" (pg. 23).

A obra possui, além disto, uma abordagem multidisciplinar, incorporando conceitos e abordagens de diferentes disciplinas das ciências humanas e está organizada, além dos elementos introdutórios, da seguinte forma.

A primeira parte, intitulada de 'Historia y Teoria en el estúdio de lo (trans)fronterizo', é composta por dois trabalhos que procuram discutir a construção do Estado Nacional e das nacionalidades na América Latina, nos séculos XVII e XIX, sua relação com a cidadania (e a constituição dos direitos a ela associados) e como a noção de coesão social pode ser importante para o estudo das fronteiras. Neste sentido, vale destacar o trabalho de Federico M. Barragán ('Cohesión territorial: un marco de referencia para el estudio de las fronteras') que propõe uma releitura da coesão social para a compreensão das fronteiras, adaptando-o à realidade e as condições latino-americanas, e indicando a necessidade de uma análise ampla do universo territorial determinado que possa orientar a construção de políticas públicas mais eficazes e, principalmente, incidir sobre a governança transfronteiriza, a partir da interação entre os mecanismos institucionais e os atores locais. Neste sentido, o autor aponta que: "La pertinencia del concepto cohesión territorial, como eje articulador de un marco general para el estudio de las fronteras, obedece, por una parte, a su alcance, pues está inserto en el debate mundial en torno a pensar y construir el desarrollo desde una perspectiva explícitamente territorial, la cual contempla múltiples actores, dimensiones y escalas. En segundo lugar, dicho concepto ofrece una formulación sintética que expresa el propósito y manifestación del paradigma del desarrollo territorial: hay desarrollo en los territorios, en tanto mejoran sus condiciones de cohesión" (pg. 52). 
A segunda parte, intitulada 'Fronteras y geopolíticas regionales' analisa a interação entre as fronteiras em duas regiões (Tríplice Fronteira na América do Sul e as fronteiras Centro-Americanas) e suas múltiplas implicações (comerciais, políticas, culturais, ...) para a geopolítica e os processos de integração regional. Nesta se destaca o trabalho de Juan Agulló ('Una revisión geopolítica de la Triple Frontera del Paraná') que, ao discutir a Tríplice Fronteira entre Brasil, Argentina e Paraguai, indica que sua especificidade "radica en el carácter intermodal de un espacio estratégico, que gracias a la explotación intensiva de algunos de sus recursos (incluyendo su posición geográfica) se ha convertido en un eslabón clave de diversas cadenas internacionales" (pg. 59).

Desta forma, tal situação implica numa redefinição de tal concepção pois tal região se constitui num espaço estratégico, único e dinâmico, que transcende ao aspecto administrativo. Sendo assim, o autor considera que sua dinâmica futura estará associada à manutenção de sua condição de área administrativa, hegemonizada pelos interesses brasileiros e voltada ao desenvolvimento econômico da região Centro-Sul do país, ou se, pelo contrário, será capaz de adquirir uma relativa autonomia e uma integração intensiva, em termos regionais, constituindo-se num corredor comercial integrado aos interesses globais, que pode desnacionalizar, modernizar ou unificar tal zona, aprofundando seu caráter excepcional.

A terceira parte, denominada de 'Fronteras y nuevos regionalismos', se propõe a realizar um balanço do regionalismo e compreender a inserção, da América Central, nos novos arranjos integracionistas que estão emergindo neste novo século (a Aliança do Pacífico, principalmente). Nesta, pode ser destacado, além do balanço da política externa brasileira recente e sua atuação ativa e global, o trabalho de Gustavo M. de Souza ('Integração ou regionalismo? Estudando fronteiras da América Latina') que procura analisar os arranjos transfronteiriços a partir das dinâmicas regionais, fundamentando-se na perspectiva dos novos regionalismos.

Para tanto, discute os conceitos de integração e fronteiras, procurando definir uma agenda que possa captar os novos processos e que se fundamenta no conceito de 'Regionalismo Transfronteiriço' definido como: "O chamado regionalismo transfronteiriço, em comparação com o macrorregionalismo, deve 
ser visto como uma série de processos mais espontâneos e endógenos, levados a cabo por agentes da sociedade civil, do mercado e do Estado, que organizam redes - ora formais, ora informais - de ação conjunta ou de cooperação. Em outras palavras, são processos que vão além da simples demanda por mais regionalismo (que, na teoria da integração, seria introduzida apenas pelas elites); são também respostas e reações ao regionalismo de maior escala e, por isso, podem ser categorizados como dinâmicas de regionalização, ou seja, de construção regional (region-building)" (pg. 129).

A parte seguinte, intitulada 'Política Internacional y nuevas modalidades de Integración Regional', analisa os mais recentes acordos internacionais de integração, a construção da agenda internacional para 2030 (a partir dos conflitos Norte-Sul) e, principalmente, a inserção brasileiras nestes novos processos e a tentativa de construção de uma liderança regional e global. Neste sentido, merece destaque o trabalho de Roberto G. Menezes e Karina L. P. Mariano ('O Brasile a trajetória recente da Integração Sul-americana 2008-2015: liderança, competição e novos rumos') que discute a atuação brasileira na América do Sul e seus impactos para sua projeção regional e global, bem como os desafios para sua continuidade.

Além deste, também se destaca o trabalho de Shiguenoli Miyamoto ('O Brasil como ator global: expectativas e dificuldades') que, ao analisar as expectativas e potenciais (limitados) e as condições e dificuldades (amplas), apesar do dinamismo recente, que poderiam tornar o Brasil uma potência global conclui que: "Em conjunto, tais fatos têm contribuído para aumentar o descrédito da capacidade brasileira em atuar no grande jogo das Relações Internacionais, como parceiro capaz de ajudar a definir e decidir os rumos do mundo. O Brasil não é, certamente, um anão diplomático, mas encontra-se bem distante da categoria de potência com responsabilidades globais. Pode-se afirmar que, mesmo em termos de seu entorno regional, nos últimos anos o Brasil tem perdido espaço considerável como grande país que sempre se considerou" (pg. 183).

A quinta parte, denominada de 'Etnias, gênero, juventudes, migraciones y espacios transfronterizos', discute como os processos associados às categorias acima tem impactado os espaços transfronteiriços na região. Desta forma, introduz uma série de novos elementos que nos permitem compreender tal 
dinâmica e interação, incorporando elementos do feminismo e da migração afrodescendente e juvenil e, principalmente, destacando a emergência da temática indígena, considerando o processo de empoderamento ocorridos em Bolívia e Equador, dentre outros, e sua relação com a integração regional.

Neste sentido, três trabalhos analisam a inserção indígena, discutindo sua resistência, sua interação na zona entre Brasil e Venezuela e sua mobilização diante dos processos de iniciativas energéticas na Mesoamérica, destacando que: "En ese sentido, es necesario emprender una transformación que inicie con un verdadero reconocimiento y concesión plena, así como facultar a las poblaciones indígenas para auto determinarse libremente en lo económico, político y social, pero con una base que garantice el respeto de sus derechos humanos" (pg. 220).

A última parte, intitulada 'Cambio climático, turismo y espacios transfronterizos', analisa como estas duas temáticas (mudança climática e turismo) incidem sobre tais espaços, discutindo algumas experiências na bacia do Rio Oiapoque e na zona fronteiriça entre Panamá e Costa Rica. Os trabalhos desta seção demonstram a necessidade de compreender as debilidades e potencialidades locais para o desenvolvimento de políticas territoriais associadas ao turismo e a experiência de um espaço transfronteiriço para se adaptar as mudanças climáticas, através do desenvolvimento de inúmeros mecanismos, dentre eles a captação e a utilização apropriada de águas pluviais (SCALL).

Como se pode observar, a obra se destaca pela abrangência, diversidade e pertinência das temáticas discutidas. Além disto, os trabalhos possuem uma análise multidimensional e multidisciplinar e apresentam um fio condutor fundamentado na abordagem decolonial. Ainda, tais trabalhos se interagem ao combinar, em maior ou menor medida, o tratamento histórico dos temas mencionados (Estado, Fronteiras, Integração, dentre outros) com a incorporação de análises e abordagens contemporâneas, além de realçar as temáticas emergentes para a compreensão dos espaços transfronteiriços. Finalmente, a obra possibilita uma efetiva aproximação e maior conhecimento dos principais processos de interação em tais espaços, tanto na América do Sul como na América Central, permitindo a construção de uma perspectiva latino-americana para a análise apropriada da realidade regional e local. 
Apesar disto, algumas temáticas ou elementos poderiam ser aprofundados. Neste sentido, há uma relativa ausência de regiões e processos da América do Sul, relacionados a outros espaços transfronteiriços, a descontinuidade de algumas experiências e aos conflitos derivados do compartilhamento de bens comuns, como na instalação de uma indústria de celulose entre Uruguai e Argentina. Associado a isto, pode-se apontar a ausência de reflexões relacionadas aos conflitos que emergem em tais zonas, aos enfrentamentos geopolíticos ou desafios importantes como o desenvolvimento de políticas públicas conjuntas, a expansão da violência e do tráfico de drogas. Finalmente, considerando o contexto mais recente e a ascensão de governos conservadores, convém destacar que os limites estruturais dos processos de integração na região, perceptíveis nas diversas experiências do século passado, poderiam ser aprofundados, bem como os impactos da crescente presença chinesa em tais processos.

Em suma, trata-se de uma obra importante que demonstra a necessidade de continuidade de pesquisas e reflexões sobre os espaços transfronteiriços, indicando que a emergência de uma perspectiva e unidade latino-americana, neste novo século, é fundamental para a continuidade dos processos de integração regional, superando a desconfiança, o desinteresse e a competição dos nacionalismos retrógrados.

Recebido em 14 de junho de 2017. Aprovado em 13 de outubro de 2017. 